\title{
LA CASA Y SU DIMENSIÓN FANTÁSTICA EN EL CUARTO DE VIDRIO, DE NORAH LANGE \\ THE HOUSE AND ITS FANTASTIC DIMENSION IN EL CUARTO DE VIDRIO BY NORAH LANGE
}

\author{
María Cecilia Ferreira Prado \\ Universidad de las Islas Baleares
}

\begin{abstract}
RESUMEN
El cuarto de vidrio (póstuma-2006) es la última novela de la escritora argentina Norah Lange. En ella se privilegia el espacio de la casa, la cual aparece aquí profundamente personificada, lo que tiñe el total del relato del sello fantástico que caracteriza a los escritores del boom. Lange reanuda, en esta novela, la estética de lo increíble que se había iniciado en Antes que mueran (1944), había conocido el éxito y el reconocimiento con Personas en la sala (1950), y había llegado a Los dos retratos (1956), sin que la crítica literaria se hubiera percatado de que estábamos ante una literatura plenamente fantástica o, dicho de otro modo, que sin descifrar ese elemento fantástico no se podía interpretar el sentido último de la narrativa de Lange; una estética que se inserta en la línea de la literatura fantástica promocionada por su primo político Jorge Luis Borges y que tuvo amplia repercusión en Hispanoamérica, especialmente en el Río de la Plata.
\end{abstract}

Palabras clave: Hispanoamérica, Literatura fantástica, Norah Lange, novela, casa.

\section{Abstract}

El cuarto de vidrio (posthumous work-2006) is the last novel of the Argentine writer Norah Lange. In it is privileged the space of the house, which appears here deeply personified, which dyes the history of the fantastic seal that characterizes the writers of the Boom. In this novel, Lange reiterates the aesthetics of the incredible stories, that had begun in Antes que mueran (1944), had known success and recognition with Personas en la sala (1950), and had come to Los dos retratos (1956), without the literary criticism having realized that we were in front of a totally fantastic literature or, in other words, that without deciphering that fantastic element could not be interpreted the ultimate meaning of Lange's narrative;

Recibido: 26-10-2017 / Aceptado: 03-05-2018 
an aesthetic that is inserted in the line of fantastic literature promoted by his cousin in-law, Jorge Luis Borges, and that had wide repercussion in Hispanic America, mainly in the Río de la Plata.

KEY WORDs: Hispanic America, Fantastic Literature, Norah Lange, novel, house.

\section{INTRODUCCIÓN: EL CUARTO DE VIDRIO, ¿UNA NOVELA INCONCLUSA?}

La muerte de Oliverio Girondo ocurrida el 24 de enero de 1967 sumió a su esposa, la escritora argentina Norah Lange (Buenos Aires, 1905-1972), en una profunda melancolía no exenta de actividad creativa. En el reportaje que concede a Beatriz de Nóbile, en 1968, Lange expone algunos datos sobre sus nuevos trabajos, entre los cuales se encuentra la última novela que está escribiendo, El cuarto de vidrio:

Preparé, en estos últimos meses, una edición de las obras completas de Oliverio, otra de mis discursos y además estoy terminando una novela. Ya tiene título, se llamará El cuarto de vidrio. Tiene el mismo tono que las anteriores, pero es un poco más directa. Todavía me faltan dos capítulos. Quedará completa y publicable a fin de año. Ahora trabajo con el mismo ritmo que me impuso Oliverio. Aun en verano trabajábamos siete u ocho horas en una quinta de Pilar';

Lo cierto es que, tras el fallecimiento de la autora, en 1972, la novela quedó guardada en un cajón, inédita hasta 2006, momento en que Beatriz Viterbo Editora gracias a la intervención de Susana Lange, sobrina de la escritora- la rescata y publica, en el segundo tomo de sus Obras completas. Los 14 capítulos que integran la novela -de los cuales el primero apareció como un adelanto en el citado libro Palabras con Norah Lange, de Nóbile, y el séptimo se publicó en el diario La Nación, con el título de «La mano en el retrato» (1969) - conforman un conjunto bastante homogéneo y cerrado. En la «Nota de edición» ${ }^{2}$, se apunta que la versión mecanografiada de la obra presentaba títulos para los diversos capítulos, no obstante, se optó por suprimirlos y solo numerarlos, siguiendo el criterio de Lange en sus obras anteriores. De todos modos, los títulos originales pensados por la autora eran los siguientes: 1 «La casa»; 2 «Gabriela»; 3 «El tío en la mesa»; 4 «Yo lo conocí antes»; 5 «Emilia y yo»; 6 «La hora del caballo»; 7 «La mano en el retrato»; 8 «La enyesada»; 9 «El cuarto de vidrio»; 10 «Las trenzas»; 11 «La inyección»; 12 «Mudanza»; 13 «Visita a la casa»; 14 «La casa».

Salvo el «Epílogo» que escribe Legaz, no existen hasta el momento estudios críticos que se ocupen de analizar esta obra, por lo que mi contribución solo es un puntal de partida para futuras investigaciones. En la exposición de la crítica se introduce un interrogante, por otro lado tan habitual respecto a las obras póstumas: «como siempre nos quedará la duda sobre si su autora ha dejado concluida la novela

\footnotetext{
${ }^{1}$ B. de Nóbile, Palabras con Norah Lange, Buenos Aires, Carlos Pérez Editor, 1968, p. 26.

${ }^{2}$ A. Astutti, «Nota de edición» a El cuarto de vidrio, en N. Lange, Obras completas, tomo 2, Rosario, Beatriz Viterbo, 2006, p. 564.
} 
o pensaba seguirla, o la acabó abruptamente» ${ }^{3}$. De igual modo, la editora, Adriana Astutti, también manifiesta serias dudas sobre si la novela estaba terminada. Es indudable que la autora tenía pensado realizar algunos cambios. Así, por ejemplo, la editora señala que:

En el capítulo 14, una anotación entre paréntesis ubicada cinco espacios por debajo del final de la novela en la versión mecanografiada anota: «(Más confusión entre la casa donde están y la casa de antes?)», sugiriendo que la novela podría extenderse o incluso que los capítulos finales admitirían, quizá, otro orden ${ }^{4}$.

Sin embargo, cabe mencionar que ya al principio de este capítulo existe una ambigüedad entre la casa del río y la casa de antes: la narradora cierra una puerta confundiendo las dos casas: «Pensé que comenzaría a mirarme mientras cerraba la puerta, pero después de unos segundos, la puerta que se cerró no era esa ni tampoco se parecía a la del comedor en esa hora pesada del almuerzo, con costumbres recién adquiridas y al descuido, de casa pasajera ${ }^{5}$. Lo más probable es que Lange deseara perfeccionar algunos rasgos del texto a fin de enfatizar la oscilación ya dada.

De todas maneras, este último capítulo, tal como se nos ofrece, presenta un final más que aceptable para la novela: con el derrumbe del cuarto de vidrio, la casa elimina a los familiares molestos y el espíritu del abuelo se dispone a gobernarla. Por otro lado, el hecho de que el primer capítulo y el último tengan el mismo título: «La casa», hace pensar en la estructura circular de la obra: la historia empieza donde acaba, en la casa.

Según Susana Lange, la novela ya estaba finalizada y lista para publicar, lo cual nos reafirma en lo que habíamos conjeturado:

El Cuarto de Vidrio fue el último libro que escribió, y sí lo terminó. Ella siempre le mostraba los manuscritos, como para tener su invaluable opinión, a Oliverio, pero él falleció y no llegó a leer los cinco últimos capítulos. Pero le puso el punto final. A mí me consta que está terminada. Quedó por varios años en un cajón, luego yo misma la pasé a Word y se la pasé a María Elena Legaz ${ }^{6}$.

La escritura de la novela coincide con una etapa difícil en la vida de Lange, puesto que debe afrontar muchos sucesos esta vez sin el apoyo incondicional de su marido. En el epílogo a la obra, Legaz afirma que:

Norah Lange pierde mucho interés por la vida con la desaparición de su compañero, quien también había sido -como Borges en los comienzos de la

${ }^{3}$ M. E. Legaz, «Epílogo» a El cuarto de vidrio, en Norah Lange, Obras completas, tomo 2, Rosario, Beatriz Viterbo, 2006, p. 648.

${ }^{4}$ A. Astutti, «Nota de edición», ob. cit., p. 564.

${ }^{5}$ N. Lange, Obras completas, A. Astutti (ed.), Rosario, Beatriz Viterbo, Tomo II, 2006, p. 637.

${ }^{6}$ Correo electrónico emitido por Susana Lange el 22/08/2016 a las 5:12 p. m. 
creación- uno de sus críticos más rigurosos. No asiste casi a reuniones sociales ni a encuentros literarios o artísticos y permanece como «voluntaria encerrada» en su casa de la calle Suipacha a la que finalmente abandona para trasladarse cerca de sus hermanas. En 1971, ya en una nueva vivienda de la calle Talcahuano, cuenta a Vicente Zito Lema que la casa la estaba echando con sus recuerdos y tristezas pero que 'ahora quiero terminar mi libro, ya llevo concretados nueve capítulos'. A partir de entonces, parece haber escrito los cinco siguientes hasta completar los catorce que tenemos ${ }^{7}$.

La experiencia de la casa donde vivió con Girondo, en la calle Suipacha, transida de recuerdos y gestos memorables, de aquel antiguo palacete que «la estaba echando» ${ }^{8}$, literalmente, cayéndose a pedazos, debió ser fundamental para la gestación de esta novela, donde también el espacio vertiginoso de la casa amenaza con desmoronarse? Una última obra que, por lo demás, resulta un balance de toda su producción anterior, tal como explica la crítica:

Norah Lange fusiona situaciones, personajes y técnicas similares a las de su narrativa anterior desde Cuadernos de Infancia hasta Los dos retratos, como un recuento final de este universo de ficción, en que imperan el recuerdo, el secreto, los miedos y el espacio privilegiado de la casa familiar ${ }^{10}$.

\section{El motivo de la casa encantada en la Literatura Hispanoamericana}

En El cuarto de vidrio se desarrolla el prototípico esquema narrativo de sus novelas precedentes, Personas en la sala (1950) y Los dos retratos (1956): de un modo similar a como ocurre en estas obras, la casa con sus mujeres tristes y melodramáticas que guardan secretos y la adolescente huérfana y aburrida, dedicada a espiarlas, son los personajes y el espacio donde se configura la acción. Sin embargo, a la narradora, lo que le lleva a contar la historia es la casa; y en ello sigue la estela del protagonista de Casa tomada, de Julio Cortázar, cuando en alguna parte del cuento afirma: «Pero es de la casa que me interesa hablar» ${ }^{11}$.

\footnotetext{
${ }^{7}$ M. E. Legaz, «Epílogo», ob. cit., p. 644.

${ }^{8}$ M. E. Legaz, «Epílogo», ob. cit., p. 644.

${ }^{9}$ En este sentido, al límite de la leyenda, algunos biógrafos indican que la casa de Suipacha, en la que vivía el matrimonio Girondo-Lange, «Era un petit hotel más bien extraño [...]. Dicen que tenía fantasmas y algunos antiguos ahorcados que solían quejarse. La buena y pobrísima gente de los conventillos aledaños solía escucharlos», M. E. de Miguel, Norah Lange. Una biografía, Barcelona, Planeta, 1991, p. 173.

${ }^{10}$ M. E. Legaz, «Epílogo», ob. cit., p. 644.

${ }^{11}$ J. Cortázar, El perseguidor y otros relatos, Barcelona, Bruguera, 1980, p. 27. Cortázar publica su primer libro de cuentos, Bestiario, en 1951. Esta primera colección de relatos está marcada por la tendencia fantástica que luego prolongará y perfeccionará a lo largo de su narrativa. Entre todos estos cuentos se encuentra la famosa «Casa tomada» que tanto gustaría a Borges, de ahí que en 1946 el escritor de El Aleph decidiera publicarla en su revista Los anales de Buenos Aires. El cuento narra la historia de dos hermanos que viven en una casa antigua dominada por extrañas presencias. Muchos de los rasgos cortazarianos del relato ya se perciben, en general, en la obra vanguardista de Lange: la casa como
} 
La extravagancia de la casa en El cuarto de vidrio se resalta desde que está profundamente humanizada - hasta tal punto que funciona como un personaje más de la historia-, poseída de sentimientos, personalidad, deseos y aprensiones; incluso la joven le concede algún que otro movimiento nocturno, lo que la lleva a interactuar con ella y a desarrollar una especie de juego donde la complicidad y el cariño son manifiestos. Así, si en las novelas anteriores lo fantástico provenía del movimiento inexplicable en retratos y fotografías, aquí lo que se mueve es la casa, que encarna, en gran medida, el sentir y el pensar de la narradora. Por tanto, el espacio resulta enteramente fantástico como consecuencia de esta personificación tan acusada en la casa, que ejerce además un influjo nefasto en los personajes adultos, siempre al borde de una muerte segura.

Debido a la singularidad de este entorno peligroso y cambiante que redunda en una dimensión desconocida - al menos eso es lo que sabemos por voz de la narradora- esta última novela de Lange ejemplifica un tema, aunque no sea el único ni el principal, de larga tradición en la literatura fantástica: la casa antigua posesa, que es una versión modernizada del castillo embrujado de la novela gótica inglesa, cuyos orígenes se remontan a El Castillo de Otranto (1764), de Horace Walpole, obra señera con que se inicia el género. La literatura anglosajona gustó mucho de este tipo de moradas ruinosas e inquietantes, con el añadido, a veces, de un posible derrumbe: «La caída de la casa Usher», de Poe; la casa del «Ciento de Sutpen» en jAbsalón, Absalón!, de Faulkner ${ }^{12}$ y «La casa encantada» de Woolf, son buen ejemplo de ello. Pero también encontramos numerosos casos de viviendas maravillosas o sobrenaturales en la literatura hispanoamericana, desde Manuel Mujica Láinez con La casa -novela que resulta increíble porque la narradora es justamente la casa que nos cuenta la historia de la familia en retrospectiva, momentos antes de ser tirada abajo-, pasando por el gran número de casas enigmáticas, con sortilegio, de Felisberto Hernández, como la antigua casona de «El balcón» ${ }^{13}$, donde un viejo balcón se suicida por amor, así se deja

espacio privilegiado, los personajes ordinarios que mantienen una rutina, el conflicto doméstico y psicológico, el detalle intrascendente; se crea un entorno realista para abolir la distancia entre personaje y lector y, en ese contexto del vivir cotidiano, va a hacer su aparición lo fantástico, gradualmente, imperceptiblemente, en medio de un ambiente denso y perturbador. Personas en la sala (1950), Los dos retratos (1956) y El cuarto de vidrio (póstuma, 2006), salvando las distancias, muy bien pudieran ponerse en relación con esta primera obra de Cortázar, puesto que ambos autores recrean en la diégesis una atmósfera rarificada, surgida en medio de la cotidianidad de lo que podría considerarse, al menos en apariencia, una casa posesa.

${ }^{12}$ La casa del Ciento de Sutpen está profundamente personificada; quizás porque el patriarca la construyera con sus propias manos, ha adquirido muchos de sus rasgos, extendiendo su idiosincrasia y su forma de pensar: "“¿Qué dices?, pregunté. "No suba, Rosa." Eso fue lo que dijo: el silencio, la quietud, y otra vez me pareció que no era ella quien hablaba, sino la casa misma, la casa que él levantó, edificada en torno suyo como una secreción de su cuerpo, como si sus sudores hubiesen producido un cascarón complementario, una suerte de capullo», W. Faulkner, jAbsalón, Absalón!, Barcelona, RBA, 1995, p. 123.

${ }^{13}$ El cuento pertenece al libro Nadie encendía las lámparas (1947), que contó con el apoyo de Oliverio Girondo para ser publicado. Cuando Lange y Girondo realizan un viaje en 1948 para pasar una 
caer, lo que tendría algún paralelismo con El cuarto de vidrio de Lange; hasta llegar a cuentos clave de la literatura argentina como la ya mencionada "Casa tomada», de Julio Cortázar, con la expulsión gradual y sistemática de los dos hermanos sobre los que planea la sospechosa sombra del incesto, o «El Aleph», de Borges, donde el chalet que pretende salvar el poetastro - primo de Beatriz Viterbo-, con su fantástico espejo-umbral ${ }^{14}$ de nombre homónimo, será también carne de escombros. En fin, no se puede decir que Norah Lange no tuvo donde inspirarse, además de haber podido aprovechar, como se ha visto, su propia experiencia personal en relación con las casas. Sobre este último aspecto, hay pruebas sobradas en los textos autobiográficos de Antes que mueran ${ }^{15}$ (1944), donde encontramos el espacio mítico de la casa, ya al borde del derrumbe, incluso, a veces, habitado por espectros. Creo que, a pesar de las diferencias argumentales y estilísticas que hay entre unos relatos y otros, todos los ejemplos ofrecidos coinciden al menos en un punto: la casa es fantástica por sí misma, su espacio es lo fantástico, independientemente de que contenga o no fantasmas u otros seres enigmáticos. Los diferentes espacios por los que transitan los personajes solo pueden ser experimentados como irreales, como una dimensión inasumible de lo Otro, porque presentan zonas de ambigüedad por donde se filtra lo increíble: puertas y ventanas que se abren por sí solas, ruidos escalofriantes, umbrales al más allá, etc., manifestando una extrañeza y una densidad emocional que escapa de la lógica del mundo. De tal manera, el espacio cotidiano se ve asaltado por fenómenos que

temporada en Europa tienen la oportunidad de conocer a Supervielle y a «ese gran escritor que es Felisberto Hernández [...]. Gracias a la intervención de Girondo, [...] logra publicar Nadie encendía las lámparas (1947) en la editorial Sudamericana», B. de Nóbile, Palabras con Norah Lange, ob. cit., p. 22 El uruguayo cuenta en su haber con un buen número de cuentos de matiz fantástico. Su obra, como la producción madura de Lange, incide en el extrañamiento de lo cotidiano, en el animismo tan característico de nuestra autora, un animismo que humaniza los objetos dotándolos de ternura y sentimientos. Los objetos como poseedores privilegiados del secreto de sus dueños pueblan las páginas de sus libros y son muchas veces protagonistas. También los ambientes interiores de las casas antiguas de Buenos Aires, con sus objetos y enseres característicos, sus típicas solteronas o viudas afincadas en un pasado remoto más prestigioso y más noble, parecen un referente indiscutible en las obras de Lange. Le falta a nuestra autora, la mirada irónica de Hernández, el toque de humor fino y preciso, en ocasiones burlón, que utiliza para desdramatizar cuando la situación lo requiere.

${ }^{14}$ R. Ceserani, en Lo fantástico, Madrid, Visor, 1999, p. 107, afirma que «A menudo hemos encontrado, en los cuentos fantásticos que hemos leído, ejemplos de [...] pasos de umbral, por ejemplo, de la dimensión de la realidad a la del sueño, a la de la pesadilla, o a la de la locura». El crítico expone un cambio de código de un umbral a otro (ya mencionado por Lugnani): «El umbral entre una dimensión y otra, entre lo idéntico y lo otro, es también, a fin de cuentas, el umbral entre lo que está codificado y lo que no está (lo que todavía no está o lo que ya no está) codificado» (p. 107). T. Todorov, por su parte, menciona ciertos objetos (lentes, espejos, prismáticos) que posibilitan la entrada en lo maravilloso, en Introducción a la literatura fantástica, Buenos Aires, Tiempo Contemporáneo, 1974 [1ªed.1970], pp. 145-147.

${ }^{15}$ En Antes que mueran se recogen numerosos casos de viviendas con rasgos sobrenaturales. Así se encuentran casas a punto de desmoronarse: «antes que el martillo la horade en un costado, sabrá reunir, rápidamente, lo que convivió en ella, para dejarse caer, henchida y sin orgullo —atónita y tierna sucesión de ladrillos-, sobre nuestros rostros antiguos» (p. 61); casas con paredes y pisos que se mueven: «las paredes cambian de sitio cada vez que intentas probarte su muerte [...] antes de que faltara el piso inmóvil que ya no se mueve porque sólo le falta regresar,» (p. 18); y casas habitadas por espíritus: «cerré la ventana y sentí que algo permaneció encerrado dentro del cuarto» (p. 64); «Los vi irrumpir en onduladas y rápidas sucesiones de ojos, de labios, de cabellos [...] pasaron arremolinados en dulce vorágine, traspasando los muebles,» (p. 102), en N. Lange, Obras completas, ob. cit. 
trastornan su estabilidad, amenazando la vida o la salud mental de los moradores.

\section{LA PROSOPOPEYA Y LA CAUSALIDAD MÁGICA}

La anécdota de El cuarto de vidrio es mínima, porque lo que le interesa a la autora, más que el desarrollo de los hechos, es crear un ambiente vertiginoso de miedo y desasosiego: tras la muerte de sus padres, la narradora-protagonista de esta historia y su hermana Emilia, ambas adolescentes, deben aprender a convivir con el tío Juan, su mujer Andrea y la hermana soltera de esta, Gabriela —enamorada de su cuñadoque han venido expresamente a cuidarlas a la ruinosa mansión familiar en que viven. La familia almuerza, merienda y cena en el cuarto de vidrio, que da título a la obra, antigua terraza luego acristalada, que los tíos emplean como salón comedor. El insólito recinto de paredes de cristal es receptáculo de los más oscuros deseos de la joven que, viendo como sus tíos se enseñorean de todo, fantasea con que caigan al vacío. Así, la casa, mal construida y añeja, se encargará de hacer sus sueños realidad, cuando por fin se derrumbe el cuarto de vidrio, con estrépito incluido.

El sucinto argumento antes planteado pone de manifiesto dos estrategias o recursos literarios que la autora abordará y aprovechará hasta la extenuación a lo largo de la obra: por un lado, la prosopopeya, técnica langeana por excelencia, presente ya en su poesía ultraísta ${ }^{16}$, y de considerable valor en lo que concierne a su producción narrativa; y, por otro, la causalidad mágica, principio recurrente en los relatos de historias prodigiosas, que el crítico Todorov (1970) analiza en su célebre Introducción a la literatura fantástica en el capítulo 7 «Los temas del yo; obra operativa al menos respecto a las novelas de Lange, cuya naturaleza fantástica, que vertebra y explica la mayoría de historias, apenas ha sido estudiada.

Por lo que concierne a la prosopopeya, se ha de señalar el hecho insólito y explícito de que la casa posee voluntad propia. La casa está profundamente personificada por la voz de la narradora, que la presenta, ya desde el inicio de la novela, como a un ser humano, no solo por lo que concierne al aspecto emocional, sino también por lo que atañe a la estructura física. Así, la muestra con sentimientos, deseos, mirada, extremidades (brazos y piernas) y capacidad de moverse por sí misma:

Fue entonces cuando resolví guardar silencio y visitar la casa de tiempo en tiempo, para verificar cómo se arreglaba sola, confinada en sí misma, cerrada, enmoheciéndose, apagándose el brillo de los cristales, extrañando desde el primer

\footnotetext{
${ }^{16}$ A diferencia de lo que sucede en relación con su prosa - donde el anclaje de la escritora en una estética determinada parece vaga o confusa - , respecto a la poesía se la suele incluir dentro del grupo ultraísta comandado por Borges, primo lejano. Este llega a Buenos Aires en 1921 para difundir la nueva tendencia aprendida en España. Lange toma de él muchas de las nuevas técnicas y publica un libro de poemas de marcado corte ultraísta La calle de la tarde (1925), prologado y elogiado por el argentino.
} 
día, acaso con deseos de darse la vuelta, o cada vez más dispuesta, en punta de pie, atisbando la calle para ver si llegábamos. ${ }^{17}$

Al final del relato, una vez consumados los hechos, se escucha una voz misteriosa que repite, como un eco, que de haber yacido allí las dos huérfanas «también hubieran tenido la impresión de caerse hacia atrás» ${ }^{18}$. Una afirmación semejante solo puede proceder de la casa, la cual pasa de ser un espacio pasivo y decorativo por donde transitan los personajes a adquirir cada vez más protagonismo, hasta convertirse en un sujeto actante, una criatura fantástica con voluntad y personalidad propia, que decidirá sobre el destino de los otros.

Respecto a la causalidad mágica, ya está implícita en el hecho dela personificación: si la casa se mueve, ello se debe a que posee vida y no a una causa natural, la cual también se apunta en determinados pasajes en los que se insiste en su deterioro; pero hay que subrayar, además, la circunstancia de cómo los sentimientos o presagios del personaje narrador finalmente se cumplen. Estos se explicitan en aquellas frases en las que la joven imagina el derrumbe y, por ende, la muerte trágica y accidental de los tíos:

Fue esa misma noche [de la muerte del padre], y, a pesar de la angustia, cuando pensé por primera vez que los tres corrían el riesgo de caer a la calle no bien el cuarto se inclinara un poco. A ellos tres, en cambio, nada pareció perturbarlos. Acodadas en nuestros sitios seguros Emilia y yo, sin embargo, los mirábamos, como desde un comienzo de despedida. Acaso porque nos sentíamos representantes verdaderos de la casa o porque la ausencia de mi padre nos dejaba más tiempo para ensayar aprensiones ${ }^{19}$.

La narradora repite este motivo un considerable número de veces a lo largo de toda la obra, como si pretendiera expresar con ello una obsesión o deseo reprimido. Así describe, con reiteración morbosa, la sensación de vértigo y profundo desasosiego que le produce este cuarto: «la casa me pareció cambiar, especialmente en el cuarto de vidrio ${ }^{20}$; «el cuarto de vidrio con su zona de peligro ${ }^{21}$; «el momento en que los tres nos confrontaran sentados del lado peligroso, del lado de los vidrios» ${ }^{22}$; «la certidumbre de que, al aproximarnos mucho a las ventanas, no sería difícil que alguien cayera a la calle» ${ }^{23}$; «quienes se sentaban de espaldas a la calle parecían encontrarse al borde de

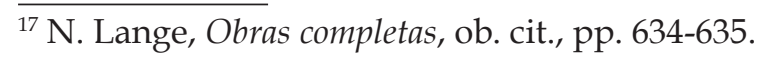

${ }^{18}$ N. Lange, Obras completas, ob. cit., p. 640.

${ }^{19}$ N. Lange, Obras completas, ob. cit., p. 610.

${ }^{20}$ N. Lange, Obras completas, ob. cit., p. 566.

${ }^{21}$ N. Lange, Obras completas, ob. cit., p. 566.

${ }^{22}$ N. Lange, Obras completas, ob. cit., p. 583.

${ }^{23}$ N. Lange, Obras completas, ob. cit., p. 608.
} 
un invisible precipicio» ${ }^{24}$; «casi podría haber exclamado: ¡cuidado! cuando veía a mi tío Juan, a Andrea y a Gabriela, echar las sillas hacia atrás, y abandonar la mesa sin siquiera mirar hacia los vidrios, tan intensa era la posibilidad de que cayesen» ${ }^{25}$; «Al mirarlos, sentados a la mesa, casi como instalados sobre un vacío próximo» ${ }^{26}$.

La acotación, en algunos pasajes, «de que la mesa se inclinaba demasiado» ${ }^{27}$ aproxima de un modo plástico y visual el futuro derrumbe que tendrá lugar cuando los tres se caigan con la terraza. Por supuesto, el hecho de que una habitación se desplome no tiene nada de particular, pero aquí el siniestro obedece a leyes desconocidas y se relaciona más que con la antigüedad o mala construcción de la casa - lo que entraría dentro de una lógica realista-con los deseos compulsivos de la joven (o de la casa), la cual, incapaz de confesarse a sí misma lo que en verdad siente, expresa estos sentimientos desplazándolos o adjudicándolos a la vivienda. Es en este marco de incertidumbre ${ }^{28}$ y de asombrosa causalidad mágica cuando el texto de Lange adquiere el máximo valor compositivo en lo que respecta al término «fantástico» ${ }^{29}$. Al acabar la historia, cuando se produzca por fin el estallido, ese «estrépito más fuerte capaz de clausurar todas las puertas» ${ }^{30}$, lo que para algunos será un simple derrumbe producto del azar, para otros será la consecuencia de las premoniciones nefastas de la joven (la casualidad convertida en causalidad); una suerte de «pan-determinismo»" en palabras de Todorov, donde se constata además que todo se corresponde y que «el paso

\footnotetext{
${ }^{24}$ N. Lange, Obras completas, ob. cit., p. 609.

${ }^{25}$ N. Lange, Obras completas, ob. cit., p. 614.

${ }^{26}$ N. Lange, Obras completas, ob. cit., p. 615.

${ }^{27}$ N. Lange, Obras completas, ob. cit., p. 609.

${ }^{28}$ Para Todorov, sin la incertidumbre o vacilación, no hay literatura fantástica: «lo fantástico no dura más que el tiempo de una vacilación: vacilación común al lector y al personaje, que deben decidir si lo que perciben proviene o no de la "realidad", tal como existe para la opinión corriente.». Si al finalizar la historia - o en algún momento de la narración - el personaje o el lector salen de la duda y deciden que el hecho extraño no puede ser explicado mediante leyes naturales entraríamos en el género de lo maravilloso; si, en cambio, concluye que se trata de un acontecimiento empíricamente demostrable, la narración pertenecería al género de lo extraño así, «Lo fantástico tiene pues una vida llena de peligros, y puede desvanecerse en cualquier momento», T. Todorov, Introducción a la literatura fantástica, ob. cit., p. 53.
}

${ }^{29}$ En sintonía con los cuentos fantásticos de Borges, Norah Lange comenzó a escribir literatura fantástica a partir de la década del 40, con obras como Antes que mueran (1944), Personas en la sala (1950) y Los dos retratos (1956). Véanse, sobre este rasgo fantástico dos artículos de mi autoría: «El retrato y sus galerías interiores: lo fantástico-extraño en Personas en la sala, de Norah Lange», Monteagudo, 23 (2018), [en prensa], y «Una autobiografía fantástica de Norah Lange: Antes que mueran», Estudios Románicos, 26 (2017), pp. 171-182.

${ }^{30}$ N. Lange, Obras completas, ob. cit., p. 641.

${ }^{31} \mathrm{El}$ «pan-determinismo», tal como explica Todorov, significa que no existe el azar, la casualidad, sino que todo lo que sucede de forma casual tiene una razón de ser que incide en lo fantástico. En el «pandeterminismo: todo, hasta el encuentro de las diversas series causales (o azar), debe tener su causa, en el sentido pleno del término, aun cuando ésta no sea sino de orden sobrenatural.», en Introducción a la literatura fantástica, ob. cit., p. 133. 
del espíritu a la materia se ha vuelto posible» ${ }^{32}$. Sin embargo, la acentuada personificación de la casa, con sus movimientos increíbles y su estremecedora voz de ultratumba al final de la obra, más la presencia fantasmal del abuelo, asimilado a la caña tacuara ${ }^{33}$, impiden clasificar la novela como un texto fantástico puro e inclinan el relato hacia una versión maravillosa ${ }^{34}$.

\section{El CONFLicto Que desata Lo FANTÁstico}

El sentimiento fantástico surge como consecuencia de un conflicto que antes no existía. Después de insistir en la impresión paranormal de que el piso se inclina demasiado, la narradora afirma: «lo extraño fue que nunca reflexioné de esa manera durante los dos años que vivimos en esa casa con nuestros padres. Tal vez sus presencias serenas, sin dobleces ni ocultamientos, bastaran para tornar natural cualquier acontecimiento» ${ }^{35}$. El gran afecto de la dueña hacia su propia casa corre parejo a la angustia contenida, silenciada en la novela, por la muerte de los padres, una conmoción que, en definitiva, es lo que desencadena esa inmersión en lo fantástico, porque tal como reconoce la narradora «era una casa hasta el llanto, aunque no lloré por ella» ${ }^{36}$. A esta desazón hay que sumar el fastidio de las diversas costumbres nuevas que vienen a imponer los tíos y que la joven «deshacía y daba vuelta,», por ejemplo, cuando «alguien retiró el florero alto o cambió de sitio la biblioteca» ${ }^{37}$. También el hecho de que la obliguen a mudarse a la detestable casa del río, que ella considera mediocre e inauténtica, mientras Gabriela permanece en la que es suya, «a sus anchas detrás del cristal, como propietaria de todas las ventanas ${ }^{38} »$, trastoca la vida del personaje y

\footnotetext{
${ }^{32}$ T. Todorov, Introducción a la literatura fantástica, ob. cit., p. 137.

${ }^{33}$ La caña tacuara, cetro simbólico del abuelo, es enterrada junto a su caballo muerto, con lo que se infiere el óbito anterior del anciano. Parece significativo, al respecto, que cuando la familia se muda a la casa del río, no se mencione en ningún momento la figura del abuelo. Por tanto, el sonido que escucha la joven de la caña tacuara, al final de la historia, anuncia la presencia fantasmal del abuelo que viene del más allá. La caña se convierte así, empleando un término de Mario Ceserani, en un objeto mediador «que, obtenido en la dimensión sobrenatural y trasladado al mundo cotidiano, probaría de manera fehaciente que el personaje "ha realizado efectivamente un viaje, ha entrado en la dimensión de otra realidad"». El objeto sirve para dar mayor verosimilitud al componente fantástico y por ende al relato; en M. Ceserani, Lo fantástico, ob. cit. p. 108.

${ }^{34}$ Lo «fantástico-maravilloso» tiene cabida en aquella «clase de relatos que se presentan como fantásticos y que terminan con la aceptación de lo sobrenatural», T. Todorov, Introducción a la literatura fantástica, ob. cit., p. 65. Cabe señalar que, pese a su ingrediente maravilloso, la novela de Lange no pertenece al género de lo maravilloso-puro, porque existe, en cierta medida, la vacilación del lector y porque el mundo en el que se mueven los personajes es casi una reproducción de nuestro mundo cotidiano, regido por leyes racionales.
}

${ }^{35}$ N. Lange, Obras completas, ob. cit., p. 609.

${ }^{36}$ N. Lange, Obras completas, ob. cit., p. 566.

${ }^{37}$ N. Lange, Obras completas, ob. cit., p. 615.

${ }^{38}$ N. Lange, Obras completas, ob. cit., p. 636. 
acelera, en gran medida, el desenlace. En su fuero interno, la adolescente no acepta la autoridad que ejercen los mayores sobre ella y su hermana; es la casa, en ausencia de sus padres, quien asume ese papel: «en realidad, fue la casa la que mandó siempre, en vez de nosotros. Claro que fue lo mejor que podía sucedernos, especialmente a Emilia y a mí, que nos habíamos quedado solas» ${ }^{39}$; al igual que sucedía en Personas en la sala, aquí se manifiesta la rebeldía de la adolescente, la diferencia estriba en que En el cuarto de vidrio se añade una constante lucha entre los tíos y las dos huérfanas por la posesión de la casa, con lo cual se manifiesta el conflicto de poder. Las hermanas se amparan en el dominio y la voluntad de la casa como fórmula para sobreponerse a la posible autoridad de los tíos.

\section{LA CASA Y SU DIMENSIÓN FANTÁSTICA}

La novela se inicia con la presentación de la casa, una mansión antigua de grandes longitudes que se deja recorrer de extremo a extremo. No solo el espacio produce vértigo y cambios anímicos en los personajes, miedos, deseos y rechazos inconscientes: «el temor también podía basarse en que — con frecuencia- la casa me abrumaba» ${ }^{40}$; sino que los familiares, a su vez, sin darse cuenta, influyen de forma decisiva sobre el aspecto y ambiente de la casa, la cual «sabía hasta cuándo podía atestarse de episodios, aparentemente inocentes, que después comenzarían a perturbarla ${ }^{41}$. Así, frente a todas las tensiones que se producen día a día en la familia (relacionadas con celos, envidias, amores a destiempo, intentos de asesinato, etc.), la casa se comporta como un animal incómodo que se da vuelta y cambia de pose. De ahí el componente subjetivo y fantástico de la vivienda. Son incontables las ocasiones en que la narradora describe su entorno como un espacio fluctuante, traslaticio, con paredes y cuartos que se mueven, lo que acerca a la memoria las imágenes borrosas e inestables de los sueños: «hasta el llanto podía quererla, aunque a veces se diera vuelta aprovechándose porque yo me demoraba en encender la luz» ${ }^{42}$. La singularidad de la casa, que produce sorpresa a cada instante, se acrecienta al compararla con las otras:

Conocí muchas personas que contaban cómo llegaban a sus casas y no era difícil imaginarlas abriendo la puerta del comedor, de la sala, de algún dormitorio. La nuestra también poseía todo eso, pero como dispuesto a último momento, como si desde el comienzo hubiésemos adivinado que nunca se acostumbraría ${ }^{43}$.

\footnotetext{
${ }^{39}$ N. Lange, Obras completas, ob. cit., p. 602.

${ }^{40}$ N. Lange, Obras completas, ob. cit., p. 565.

${ }^{41}$ N. Lange, Obras completas, ob. cit., p. 567.

${ }^{42}$ N. Lange, Obras completas, ob. cit., p. 567.

${ }^{43}$ N. Lange, Obras completas, ob. cit., p. 566. 
El discurso se vuelve vago y sibilino cuando se trata de describir los movimientos increíbles que realiza la casa «yo encendía la luz, esperando que se moviera. Pero la casa conocía mi juego desde cualquier distancia y a toda hora. $\mathrm{Y}$ cuando yo decidía encender la luz, aunque hubiesen pasado muchas noches, todavía la postergaba, la hacía esperar $»^{44}$. Es como si a la narradora le costara expresar de un modo coloquial y sencillo lo que han visto sus ojos, lo que ha presenciado, y debiera recurrir en su defecto a metáforas, símiles, metonimias y otras formas del sentido figurado, a fin de ofrecer una idea aproximada. Así, por ejemplo, para indicar el grado de peligrosidad y temor que inspira el recinto, desarrolla alguna que otra metáfora irracional al comparar la casa con la araña «me hacía recordar a esas grandes arañas que nos sorprenden, no bien encienden la luz, como una mancha en la pared que no puede pasar desapercibida ${ }^{45}$; la semejanza se extiende, en otra ocasión, hasta la figura más elegante del retrato, motivo central en el argumento de Personas en la sala y en Los dos retratos: «tal vez se había conformado muchos años atrás y su decencia de casa conocedora la tornaba paciente y perdonadora, como esos grandes retratos que penden en salas frescas y oscuras, recordando la gran fiesta» ${ }^{46}$. El retrato, al igual que la casa antigua, «momifican» el pasado, ambos reproducen, a su manera, con sus imágenes y objetos añejos, un tiempo remoto que ya no existe, en el que todos vivían felices.

\section{IDENTIFICACIÓN CASA-PERSONAJE: «LOS TEMAS DEL YO»}

Explica René Wellek que «los ambientes, especialmente los interiores de las casas pueden considerarse como expresiones metonímicas o metafóricas del personaje ${ }^{47}$. Esta observación puede aplicarse perfectamente a nuestra novela. La relación de dependencia entre el personaje y la casa es absoluta. La casa hará lo que la joven niña ordene, eliminará a los tíos si es preciso, porque la casa «es» de algún extraño modo la niña, y el cuarto de vidrio, con su zona de peligro acristalada, no es otra cosa que su brazo ejecutor. No en vano, en un plano físico y espiritual, la casa se le parece. La adolescente ha comenzado ese difícil proceso de cambios que la llevarán a construir su identidad, «creciendo de a pedazos» ${ }^{48}$, de igual modo que la casa, que parecía a su vez «disponer de mucho tiempo, y estaba así, completa, de pie, desproporcionada y satisfecha $»^{49}$. Por ello, la casa está afuera, pero sobre todo adentro, la casa la vive y, a su vez, ella vive intensamente su casa, es su manera de estar y de ser en el mundo:

\footnotetext{
${ }^{44}$ N. Lange, Obras completas, ob. cit., p. 568.

${ }^{45}$ N. Lange, Obras completas, ob. cit., p. 565.

${ }^{46}$ N. Lange, Obras completas, ob. cit., p. 638.

${ }^{47}$ R. Wellek y A. Warren, Teoría literaria, Madrid, Gredos, 1966, p. 265.

${ }^{48}$ N. Lange, Obras completas, ob. cit., p. 566.

${ }^{49}$ N. Lange, Obras completas, ob. cit., p. 567.
} 
«después, sólo necesité seguir mirando. La casa me devolvía la mirada como si no esperara otra cosa. Y yo me quedaba quieta, con toda la casa adentro, en torno mío» ${ }^{50}$. Es un ejemplo que ilustra magníficamente «la desaparición del límite entre sujeto y objeto» que propone Todorov ${ }^{51}$, tan habitual en los relatos fantásticos, que viene a ser una de las premisas básicas de los temas del $Y_{O^{52}}$.

La relación simbiótica con la casa es patente y bordea el ámbito de la obsesión. Ya en el primer capítulo, en medio de un texto farragoso y que parece avanzar a trompicones, la joven reconoce la conspiración entre ella y la casa y se lamenta por lo mucho que le exige, entre otras cosas, «que bajara un cuarto [el cuarto de vidrio], que se olvidara de corregir la pared recién revocada» ${ }^{53}$ a la cual cargoseaba con el peso de las plantas. Todo parece indicar que la joven aguarda en la sombra la desgracia y propicia con algún detalle el accidente. Pero son actos mínimos, insignificantes, travesuras de niña sin mayores consecuencias. Lo que al final sí decide el derrumbe es la acción definitiva de la casa, que está, como se ha expuesto, profundamente personificada y dotada de voluntad propia: porque ya la casa «se había dado vuelta y empezaba a mandar» ${ }^{54}$.

El cariño que la joven niña prodiga a la casa, aceitando puertas, lustrando molduras, jugando incluso con ella, queda justificado desde que esta encarna el espíritu de los ancestros y, por ende, es la depositaria no solo del recuerdo de sus padres, sino también de la esencia del abuelo y su animal favorito: el caballo, cuya silueta funeraria quedó grabada en el jardín. Según el concepto de cronotopo ${ }^{55}$ que ofrece Bajtín, el espacio expresa por sí solo un tiempo, en este sentido, la casa evoca el tiempo entrañable de la infancia, una época desaparecida, irrecuperable para las dos niñas, en que todos eran felices y no existía el engaño ${ }^{56}$, introducido más tarde por los

\footnotetext{
${ }^{50}$ N. Lange, Obras completas, ob. cit., p. 568.

${ }^{51}$ T. Todorov, Introducción a la literatura fantástica, ob. cit., p. 140.

${ }^{52}$ En el séptimo capítulo de su obra, Todorov se refiere a «los temas del yo» (pp. 129-148), relacionados, sobre todo, con el «pan-determinismo», «la pan-significación» y con las «metamorfosis», conceptos que indican que todo se corresponde. Las explicaciones aportadas por el búlgaro demuestran los mecanismos del modo fantástico mediante los cuales, en los relatos asombrosos, las palabras y las ideas pueden volverse perceptibles y «reales» en la modificación que sufren los objetos. Pero no solo las ideas son causantes de metamorfosis, también los sentimientos, las fantasías y, en general, todas las manifestaciones psíquicas que corresponden al mundo interior del personaje pueden provocar modificación o movimientos sorprendentes en los objetos y seres que hay alrededor. Ello se cumple porque, en ocasiones, al sujeto le es imposible diferenciar su yo, íntimo y subjetivo, de la realidad exterior que lo circunda.
}

${ }^{53}$ N. Lange, Obras completas, ob. cit., p. 567.

${ }^{54}$ N. Lange, Obras completas, ob. cit., p. 641.

${ }^{55}$ Véase M. Bajtín, «El cronotopo», en E. Sullà, Teoría de la novela: antología de textos del siglo XX, Barcelona, Crítica. 1996, pp. 63-68, donde explica que el tiempo se materializa y se hace visible en el espacio, mientras que, a su vez, el espacio es capaz de evocar por sí mismo un sentido temporal.

${ }^{56}$ En el capítulo 13 se menciona de manera insistente la palabra «engaño», con ello se sugiere la infidelidad 
tíos. Por ello, algunos sentimientos como la ternura, el amor y la complicidad que se establecen entre la dueña y su casa, se subrayan a cada instante. Así tienen lugar una serie de espionajes y procesos lúdicos en los que los momentos de luz y de sombra se alternan como obedeciendo a leyes secretas: «hasta el llanto podía quererla, aunque a veces se diera vuelta aprovechándose porque yo me demoraba en encender la luz» ${ }^{57}$; una intermitencia que pauta el movimiento de la casa —esta se movería, al parecer, en lo oscuro- y que recuerda en algún sentido el conocido juego del escondite inglés ${ }^{58}$, la joven explica: «yo encendía la luz, esperando que se moviera. Pero la casa conocía mi juego desde cualquier distancia y a toda hora ${ }^{59}$. Destaca la actitud positiva y valiente de la adolescente que en lugar de asustarse o sorprenderse frente al hecho sobrenatural lo aprovecha, consiguiendo la alianza con la casa ${ }^{60}$.

\section{LA CASA COMO SUJETO MORAL}

La idea de moralidad y buena conducta que encarna la casa condiciona los acontecimientos que se producirán en la diégesis. Los personajes están predestinados a morir desde el inicio de la obra, porque la casa no los quiere: no consiente, por ejemplo, el conflictivo trío sentimental que configuran los tíos, ni las muchas «atmósferas diferentes» que estos imprimen, como nuevos dueños, cuando se encuentran juntos comiendo. Así, el punto de vista de la narradora se identifica con la visión que la casa tiene de estos personajes, en cuyo modo de ser y comportarse siempre yace un fondo de falsedad y presunción, porque ni siquiera son capaces de «mirarse a los ojos» ${ }^{61}$; mostrándose excesivos, «acaso demasiado importantes» ${ }^{62}$. De tal modo, al principio

del tío Juan hacia su esposa Andrea; pero también el ardid de los tíos respecto a las sobrinas, que son desplazadas a una quinta como estratagema para que Gabriela se quede definitivamente con la casa.

${ }^{57}$ N. Lange, Obras completas, ob. cit., p. 567.

${ }^{58} \mathrm{El}$ escondite inglés es un juego que se hizo muy popular en Argentina. Mientras uno de los niños cuenta, con los ojos cerrados y de cara a la pared, «un, dos, tres, escondite inglés», los demás, que se hallan en la otra punta, tienen que correr hasta él para tocarlo sin ser vistos. Así, pues, cuando el niño que contaba se da vuelta, los otros deben permanecer fijos como estatuas porque el que es visto moviéndose pierde el juego y ha de comenzar desde el fondo.

${ }^{59}$ N. Lange, Obras completas, ob. cit., p. 568.

${ }^{60}$ Para Vax (citado por Belevan): «No hay verdadero fantástico sino cuando éste ha sido anhelado», H. Belevan, Teoría de lo fantástico: apuntes para una dinámica de la literatura de expresión fantástica, Barcelona, Anagrama, 1976, p. 63. La observación es necesaria: en muchos relatos fantásticos, de autores contemporáneos, se nota en los personajes esa predilección por lo fantástico que viene a llenar un vacío o a solucionar un problema. Lo fantástico deja de experimentarse con terror, abandona su situación marginal para situarse del lado del protagonista. Hay una reivindicación, en ese sentido, de la transgresión y de la ruptura con un orden racional que no logra satisfacer a los individuos en lo que concierne a sus inquietudes más íntimas. Buen ejemplo de ello es la contraposición que se establece, en la novela, entre la casa sobrenatural y otra corriente, la «casa del río», donde la protagonista toma partido a favor de la primera.

${ }^{61}$ N. Lange, Obras completas, ob. cit., p. 577.

${ }^{62}$ N. Lange, Obras completas, ob. cit., p. 577. 
de la obra, en una suerte de resumen total de la novela, la narradora expresa en pocas líneas las posibles razones de la casa para echarlos:

Tampoco era admisible exigir de la casa tantas atmósferas diferentes, que afrontara el aire de barco que prevalecía en el cuarto de vidrio [por culpa del tío Juan, ex marino], o el sitio definido para un llanto sin testigos, apenas un lamento de una persona enyesada en la habitación contigua [Andrea], mientras un caballo se asomaba a la verja porque alguien tenía capricho y alguien no se enamoraba como era debido [Gabriela] ${ }^{63}$.

La novela se convierte así en la crónica de una muerte anunciada, proclamada con insistencia por la voz de la narradora. De forma similar a como ocurre en «Casa tomada» de Julio Cortázar, con el motivo latente del incesto implícito en ese curioso $\mathrm{y}$ "silencioso matrimonio de hermanos» ${ }^{64}$, la antigua casona se porta como un sujeto moral y expulsa a sus inquilinos, lanzándolos a la calle, con la consecuencia mortal que implica este desahucio. Solo los «representantes verdaderos» ${ }^{65}$ de la mansión, es decir, los que respetan el antiguo Orden sin proponer ningún cambio, son autorizados a permanecer en ella, en ese paraíso idílico y de bienestar que metaforiza la casa. Por ello, la protagonista y su hermana Emilia pueden sentirse a gusto y a salvo: la casa las quiere, no las rechaza como a los otros. Las dos huérfanas, últimos vástagos de una genealogía exangüe, serán las encargadas de cuidar y perpetuar los recuerdos de la familia; unas tradiciones y costumbres transmitidos de generación en generación que la casa no desea que se acaben.

\section{LA CASA DE LA IMAGINACIÓN VERSUS LA CASA DEL Río}

De un modo similar a como sucediera en Personas en la sala, la narradora, junto a su hermana y al matrimonio de tíos, se traslada durante tres meses a una quinta, una casa corriente que queda en las afueras en un entorno rural. Con este repentino viaje se pretende una liberación, una resolución del conflicto sentimental que se ha instaurado en la familia por culpa de Gabriela. Pero la protagonista siente que ha viajado de un espacio positivo a otro negativo $y$, entristecida, desaprueba el cambio. Los dos espacios se oponen de manera evidente en el texto como si confrontaran o compararan dos ideologías o dos maneras distintas pensar. En un sentido más amplio, esta contraposición podría leerse como la ejemplificación de dos estilos literarios diferentes: novela vanguardista o de imaginación versus novela realista o de la tierra. De tal manera, la casa de los padres propone un espacio de imaginación y fantasía, un lugar donde todos los deseos y sueños son posibles, incluso aquellos reprimidos

\footnotetext{
${ }^{63}$ N. Lange, Obras completas, ob. cit., p. 567.

${ }^{64}$ J. Cortázar, El perseguidor y otros relatos, Barcelona, Bruguera, 1980, p. 26.

${ }^{65}$ N. Lange, Obras completas, ob. cit., p. 610.
} 
por impíos o amorales como la muerte de los tres tíos; es también un espacio lúdico y meditativo la casa de la infancia, el del recuerdo y los juegos infantiles. En contraste, la casa del río es mediocre, sin magia, todo en ella miente, decepciona, siendo de un realismo vulgar y descarado $\mathrm{y}$, sin embargo, la protagonista la siente ficticia, porque la califica de «inauténtica ${ }^{66}$, mientras que a la otra, a la suya, donde reina el juego y la fantasía, la denomina «verdadera» ${ }^{67}$. Tal como señala Roas, en la ficción fantástica se produce un desfase respecto a la percepción de lo real. La existencia de lo imposible conduce a dudar de la realidad misma. Lo irreal pasa a ser concebido como real y lo real como irreal:

Basado, por tanto, en la confrontación de lo sobrenatural y lo real dentro de un mundo ordenado y estable como pretende ser el nuestro, el relato fantástico provoca $-\mathrm{y}$, por tanto, refleja- la incertidumbre en la percepción de la realidad y del propio yo: la existencia de lo imposible, de una realidad diferente a la nuestra, conduce, por un lado, a dudar acerca de esta última y, por otro, y en directa relación con ello, a la duda acerca de nuestra propia existencia: lo irreal pasa a ser concebido como real, y lo real, como posible irrealidad ${ }^{68}$.

En este marco, la casa del río es contemplada como ajena, «pasajera e innecesaria ${ }^{69}$. El sentido de pertenencia es muy importante en la obra. Así, cuando la joven descubre que Gabriela se ha quedado en su casa como dueña y señora, mientras ella y su hermana se han visto desplazadas a la quinta, experimenta tal evento como una expropiación inadmisible y el sentimiento dominante es la repulsa: «fue al llegar a la estación cuando comencé a indignarme ${ }^{70}$. La adolescente no acepta ser despojada de lo que por derecho propio le pertenece, la casa, y reflexiona «que Gabriela luchaba por su vida, pero la casa también era importante, y yo luchaba por la casa» ${ }^{71}$.

Por otro lado, ambos espacios sirven para subrayar la indecisión de Juan —a quien se describe al principio de la obra «como un péndulo» ${ }^{72}$ - entre las dos mujeres, que ahora viven en dos casas distintas. Pero, frente a esta situación confusa que perjudica sobre todo a las dos niñas, la casa reacciona: «se da vuelta», no se queda quieta, que sería lo propio de una casa corriente, y el efecto fantástico proporciona el sentido final de la obra. La situación se agrava sin remedio porque «la casa, verdaderamente, había

\footnotetext{
${ }^{66}$ N. Lange, Obras completas, ob. cit., p. 637.

${ }^{67}$ N. Lange, Obras completas, ob. cit., p. 637.

${ }^{68}$ D. Roas, «La amenaza de lo fantástico», en D. Roas (comp.) et alii, Teorías de lo fantástico, Madrid, Arco/Libros, 2001, p. 9.

${ }^{69}$ N. Lange, Obras completas, ob. cit., p. 637.

${ }^{70}$ N. Lange, Obras completas, ob. cit., p. 636.

${ }^{71}$ N. Lange, Obras completas, ob. cit., pp. 634-635.

${ }^{72}$ N. Lange, Obras completas, ob. cit., p. 578.
} 
empezado a mandar» ${ }^{73}$. Ya en el capítulo número 1, en una especie de prolepsis de lo que será el desenlace, la narradora auguraba: «si [Gabriela] lo conoció primero estábamos seguras de que todo terminaría mal» ${ }^{74}$. La novela concluye con un estrépito final «capaz de clausurar todas las puertas» ${ }^{75}$, lo que sugiere que el cuarto de vidrio se ha desmoronado finalmente. La casa se deshace de los adultos molestos y el espíritu del abuelo - caracterizado por golpear el techo con una caña tacuara cuando necesitaba algo, pero también para llamar a silencio tras las muchas peleas-, comienza a caminar «decentemente, sin sueño» ${ }^{76}$, que es lo propio de un fantasma, restableciendo el antiguo orden moral que se había resquebrajado en la familia.

\section{LOS MECANISMOS DE LA MEMORIA: LA CASA COMO OBJETO MEMORÍSTICO}

Como suele ser habitual en la producción literaria de Norah Lange, la historia se construye a base de fragmentos recordados, entre los que median, a veces, grandes lagunas temporales. Desde el presente de la enunciación, la narradora se dirige hacia el pasado, hacia el tiempo de su lejana adolescencia, donde cree haber percibido los hechos asombrosos, relacionados con la casa y su cuarto de vidrio. El ejercicio de la memoria y los mecanismos que emplea para recuperar algunas de estas imágenes parecen haber sido gestados ya en esa época. Así, por ejemplo, a la adolescente le place recorrer las habitaciones de su casa para poder evocarlas, momentos después, desde el recuerdo: «lo simple hubiese sido pasar de un cuarto a otro y rememorar, de inmediato, el que acababa de abandonar» ${ }^{77}$; por tanto, el gusto reside más que en ver en recordar, en evocar lo observado, para reflexionar sobre ello en la intimidad de la conciencia. Y, por supuesto, la casa, enigmática, sugestiva, será el objeto fundamental, el «amuleto» que le ayudará a recordar, a rescatar ese «algo que no deseaba olvidar» ${ }^{78}$ de las zonas más recónditas del inconsciente. Por ello la narradora adulta invoca la casa, un espacio que «podía desesperar a cualquiera; no mientras la habitamos, sino más tarde, al recordarla ${ }^{79}$. El problema asoma mientras se recuerda, es así cómo surgen las revelaciones, los ademanes furtivos, la verdad que quedó escondida bajo un manto de «normalidad» y engañosa apariencia. Pero para que la casa emerja, no basta con pensarla, es necesario estar triste, seguir unos pasos, como si se asistiera a un ritual:

\footnotetext{
${ }^{73}$ N. Lange, Obras completas, ob. cit., p. 640.

${ }^{74}$ N. Lange, Obras completas, ob. cit., p. 583.

${ }^{75}$ N. Lange, Obras completas, ob. cit., p. 640.

${ }^{76}$ N. Lange, Obras completas, ob. cit., p. 641.

${ }^{77}$ N. Lange, Obras completas, ob. cit., p. 566.

${ }^{78}$ N. Lange, Obras completas, ob. cit., p. 565.

${ }^{79}$ N. Lange, Obras completas, ob. cit., p. 602. 
Nosotros conocíamos lo que la casa esperaba, las exigencias que imponía para acercarse de nuevo. Era una cuestión de comportamiento, más bien una manera especial de condolernos. Entonces, a fuerza de condolernos, la casa se aproximaba. Como cuando se murmura «adiós» muchas veces, a solas, hasta que el adiós, sin destinatario forzoso, se agranda hasta parecerse a alguien que realmente se despide, y entonces es preciso agregar «ya nunca volveré a verte». La casa había adquirido demasiadas costumbres, grandes espacios con tiempos diferentes; para recordarla necesitábamos estar juntas como si nos faltara coraje ${ }^{80}$.

De tal manera, la tristeza es la condición principal que exige la casa, una tristeza ligada a la sensación de desamparo y cobardía que impone la vida misma «como si nos faltara coraje», solo así la casa resurge en el ámbito de la memoria de la joven, con el aura protectora de una madre. Cuando por fin aparece, la narradora aclara que «su manera de acercarse no dejaba de ser especial» ${ }^{81}$; surge por partes, como flashes $\mathrm{o}$ fogonazos: «era una casa incapaz de presentarse sola, como otras casas. Acudía a los tirones, como si se ofreciese de a pedazos» ${ }^{82}$. En alguna ocasión, la casa se aproxima sin que la joven «la esperara y ya la tenía encima, pidiendo sitio, perturbándome cualquier tarea ${ }^{83}$.

Destaca esa personificación tan acusada a lo largo de la obra que tiñe todo el relato de la impronta maravillosa. La novela termina donde empezó, en la casa, con ese recuerdo obsesivo y persistente de la casa, que la obliga «a separar un cuarto, a dejarme impresionar por otro, pero sobre todo, enclaustrándome en el cuarto de vidrio, objetable y querido» ${ }^{84}$. Parece importante señalar esta frase final, este enclaustramiento simbólico de la protagonista, condenada a permanecer recluida en un único pensamiento y una sola obsesión: el cuarto de vidrio; secuela, por otro lado, tan habitual en los personajes langeanos, luego de haber sido expuestos a eventos increíbles. Recuérdese, si no, la aversión de la protagonista de Los dos retratos por colgar espejos o retratos; o el deseo final de la adolescente en Personas en la sala, consistente en olvidar los rostros «tratando de que mi mirada no los supiera de memoria» ${ }^{85}$, única opción válida, por lo demás, si es que desea curarse.

\section{CONCLUSIONES}

A lo largo del estudio, se ha destacado el motivo de la casa encantada o posesa

\footnotetext{
${ }^{80}$ N. Lange, Obras completas, ob. cit., pp. 602-603.

${ }^{81}$ N. Lange, Obras completas, ob. cit., p. 638.

${ }^{82}$ N. Lange, Obras completas, ob. cit., p. 602.

${ }^{83}$ N. Lange, Obras completas, ob. cit., p. 564.

${ }^{84}$ N. Lange, Obras completas, ob. cit., p. 641.

${ }^{85}$ N. Lange, Obras completas, ob. cit., p. 227.
} 
en El cuarto de vidrio, es decir, la casa como «personaje», como criatura fantástica. Se ha señalado, también, de qué manera y mediante qué recursos este sujeto ficticio y con voluntad propia espejea, de algún modo, la inestabilidad emocional y los deseos homicidas de la joven protagonista.

Lange reanuda, en esta novela, la estética de lo increíble que se había iniciado en Antes que mueran (1944), había conocido el éxito y el reconocimiento con Personas en la sala (1950), y había llegado a Los dos retratos (1956), sin que la crítica literaria se hubiera percatado de que estábamos ante una literatura plenamente fantástica o, dicho de otro modo, que sin descifrar ese elemento fantástico no era posible interpretar el sentido último de la narrativa de Lange; una estética que se inserta en la línea de literatura fantástica promocionada por Jorge Luis Borges (primo lejano), y que tuvo amplia repercusión en Hispanoamérica, sobre todo en el Río de la Plata.

Para lograr el efecto fantástico, la escritora hace uso de un recurso habitual ya desde su poesía: la prosopopeya. La casa está personificada al máximo por la voz de la narradora, que asegura que se mueve, sufre desplazamientos y alguna modificación en su estructura. Podría parecer que estas variaciones de la casa se deben a su antigüedad o mala construcción (opción realista), pero la narradora insiste en que la casa tiene vida y voluntad propia (opción irreal o sobrenatural), lo que despliega dos interpretaciones contrapuestas, de ahí la vacilación del lector, típica del género fantástico. Sin embargo, muchos giros y movimientos de la casa resultan tan increíbles a la luz de la razón que no alcanzan ninguna explicación. A ello debemos sumar la presencia también enigmática de las voces en eco, provenientes del más allá, y el espíritu invisible del abuelo que sale a recorrer la casa, eventos ocurridos al final de la historia, cuando ya la habitación de vidrio se ha desmoronado, acabando con la vida de los tíos. Así, pues, desde la perspectiva de Todorov, la obra pertenece al género de lo fantástico-maravilloso, ya que es imposible encontrar razones suficientes que alcancen a explicar de manera lógica y objetiva la verdadera causa de todos estos acontecimientos increíbles.

\section{Bibliografía}

Astutti, A., et alii, Promesas de tinta. Diez ensayos sobre Norah Lange, Buenos Aires, Beatriz Viterbo, 2010.

, «Nota de edición», en N. Lange, Obras completas, Rosario, Beatriz Viterbo, tomo 2, 2006, p. 564 .

BAjTín, M., «El cronotopo», en E. Sullà (ed.), Teoría de la novela: antología de textos del siglo xx, Barcelona, Crítica, 1996, pp. 63-68. 
Belevan, H., Teoría de lo fantástico: apuntes para una dinámica de la literatura de expresión fantástica, Barcelona, Anagrama, 1976.

Ceserani, R., Lo fantástico, J. Díaz de Atauri (trad.), Madrid, Visor, 1999.

CORTÁzAr, J., El perseguidor y otros relatos, Barcelona, Bruguera, 1980.

FAulKner W., jAbsalón, Absalón!, B. F. Nelson (trad.), Barcelona, RBA, 1995.

Ferreira Prado, M. C., «Paraísos femeninos en Personas en la sala, de Norah Lange», en F. López Criado (ed.) et alii, La diversidad en la literatura, el cine y la prensa española contemporánea, Santiago de Compostela, Andavira, 2015, pp. 465-472. , «El retrato y sus galerías interiores: lo fantástico-extraño en Personas en la sala, de Norah Lange», Monteagudo, 23 (2018), [en prensa].

, «Una autobiografía fantástica de Norah Lange: Antes que mueran», Estudios Románicos, 26 (2017), pp. 171-182.

Fuentes, C., La nueva novela hispanoamericana, México, Cuadernos de Joaquín Mortiz, 1988 [1 $1^{\text {a ed. } 1969] .}$

LANGe, S., Página oficial de Oliverio Girondo y Norah Lange [en línea]. Disponible en: http://www.girondo-lange.com.ar/norah-lange/cronologia/index.html. [consultado 05-10-2017]

Lange, N., Obras completas, A. Astutti (ed.), Rosario, Beatriz Viterbo, 2006.

Legaz, M. E., Escritoras en la sala. Norah Lange. (Imagen y memoria), Córdoba (Argentina), Alción, 1999.

«Epílogo», en Norah Lange, Obras completas, A. Astutti (ed.), Rosario, Beatriz Viterbo, Tomo II, 2006, pp. 643-650.

Miguel, M. E. de, Norah Lange. Una biografía, Barcelona, Planeta, 1991.

Nóbile, B. de, Palabras con Norah Lange, Buenos Aires, Carlos Pérez (ed.), 1968.

RoAs, D., «La amenaza de lo fantástico», en D. Roas (comp.) et alii, Teorías de lo fantástico, Madrid, Arco/Libros, 2001, pp. 7-44.

Todorov, T., Introducción a la literatura fantástica, S. Delpy (trad.), Buenos Aires, Tiempo Contemporáneo, 1974 [1 $1^{\text {a ed.1970]. }}$

Wellek, R. y Warren, A., Teoría literaria, Madrid, Gredos, 1966. 